\title{
DETERMINAÇÃO IMUNOHISTOQUÍMICA DA PRESENÇA DE CÉLULAS MIÓIDES EMPACIENTES SUBMETIDOS À TIMECTOMIA
}

\author{
DETERMINATION OF THE PRESENCE OF MYOID CELLS IN THE THYMUS BY \\ IMMUNOHISTOCHEMISTRY AFTER THYMECTOMY FOR MYASTHENIA GRAVIS
}

\author{
Olanrewaju Muisi Adedamola Ladipo ${ }^{1}$; Marcos Brasilino de Carvalho²; \\ Abrão Rapoport, ECBC-SP²; Victor Eduardo Arrua Arias'3; Luiz Carlos Filgueiras Leiro ${ }^{1}$
}

RESUMO: Objetivo: Detectar e quantificar células mióides em timos de pacientes com miastenia grave, estabelecendo possível correlação entre a quantidade de células mióides com variáveis demográficas e clínico-patológicas. Método: Foram analisados por meio de método imuno-histoquímico com anticorpo antidesmina (clone D33; marca Dako), timos de 22 pacientes (16 mulheres e seis homens, entre 12 e 61 anos) submetidos à timectomia, entre 1981 e 1995 , no Serviço de Cirurgia Torácica do Hospital Heliópolis como parte do tratamento de miastenia grave. Resultados: As maiores médias de células mióides foram encontrados em timos dos pacientes da raça negra $(29,4: 17,8)$, do sexo feminino $(23,2: 13,0)$ e com faixa etária entre 60 e 80 anos (média de 33,0). Pela classificação clínica da Fundação de Miastenia Grave da América (MGFA), a maior média de células mióides $(26,7)$ encontra-se na classe IIIa, sendo do tipo histológico de hiperplasia verdadeira (média 42,0). As células mióides foram identificadas em 11 timos com hiperplasia linfóide, três hiperplasias verdadeiras e em quatro timos normais. Os timomas malignos (três) e um timo normal não apresentaram células mióides. Conclusão: As células mióides podem ser identificadas e quantificadas pelo método imuno-histoquímico com anticorpo antidesmina, porém não existe correlação entre a quantidade de células mióides e as variáveis demográficas, clínico-patológicas. Elas não foram identificadas no timoma fusocelular.

Descritores: Células mióides; Timos; Imunohistoquímica.

\section{INTRODUÇÃO}

O primeiro relato sobre a relação da miastenia grave com o timo foi feito por Oppenheim em 1899, que em uma necrópsia, notou um tumor de mediastino (linfossarcoma) em paciente com sintomas similares ao que, posteriormente, foi denominado miastenia grave ${ }^{1,2}$. Buzzard (1905) em uma análise clínico - patológica de pacientes miastênicos, observou hiperplasia tímica e infiltração de linfócitos nos músculos esqueléticos ${ }^{3}$. Estudo anatomopatológico de timos de pacientes miastênicos, confirmou as alterações patológicas e verificou que $70 \%$ dos timos dos pacientes apresentaram hiperplasia folicular linfóide, $10 \%$ de timoma e $20 \%$ de atrofia tímica4.

Estudos do mecanismo auto-imune da placa motora e sua relação com a patogênese da miastenia grave, serviram de base para os trabalhos que investigaram as células primordiais tímicas de humanos e animais ${ }^{5-8}$. As células mióides foram reconhecidas e sugeridas como prováveis elementos que reagiriam com anticorpos antimúsculo ${ }^{9,10}$.

As origens e as funções das células mióides na patogênese da miastenia grave ainda são controversas e representam uma questão aberta na literatura médica. Há observação de mais células mióides em timos miastênicos em uma análise comparativa de timos miastênicos e não miastênicos, mas não há confirmação da hipótese de auto-sensibilização das células mióides pois não houve diferença em suas quantidades nos dois grupos de 47 pacientes com miastenia grave e 15 controles embora as células dos miastênicos apresentassem mais receptores de acetilcolina ${ }^{11,12}$.

A utilização de anticorpo antidesmina mostrou-se mais apropriada à identificação das células mióides em razão da maior quantidade de desmina do que de mioglobina encontradas nas células mióides ${ }^{13,14}$.

Diante desses fatos, propusemo-nos a detectar e quantificar por meio do método imuno-histoquímico com anticorpo antidesmina, células mióides e estabelecer a possível correlação entre a quantidade de células mióides por unidade de área em cortes histológicos de timos e variáveis demográficas, clínicas e patológicas nos timos dos pacientes submetidos à timectomia para tratamento de miastenia grave.

\section{MÉTODO}

A casuística foi composta de 22 pacientes encaminhados pelo Departamento de Neurologia e Neurocirurgia do Hospital Heliópolis e submetidos à timectomia, entre 1981 e 1995, no Departamento de Cirurgia Torácica do Hospital Heliópolis como parte do tratamento de miastenia grave.

Os pacientes deste estudo constituíram-se de 16 mulheres (73\%) e seis homens (27\%). O paciente mais jovem

1. Cirurgião do Departamento de Cirurgia Torácica do Hospital Heliópolis, São Paulo - SP.

2. Cirurgião do Departamento de Cirurgia de Cabeça e Pescoço e Otorrinolaringologia do Hospital Heliópolis, São Paulo - SP.

3. Patologista do Instituto Adolfo Lutz - SP.

Recebido em 23/05/2003

Aceito para publicação em 21/11/2003

Trabalho realizado no Departamento de Cirurgia Torácica do Hospital Heliópolis, São Paulo, SP, Brasil. 
tinha 12 anos e o mais idoso 61 anos, a média foi 28,9 anos e a mediana de 26,5 anos. O maior grupo era feminino, na faixa etária de 20 a 40 anos. A maioria dos pacientes era da raça branca, 17 casos $(77,3 \%)$, e cinco da raça negra $(22,7 \%)$. O diagnóstico de miastenia grave foi realizado no Departamento de Neurologia e Neurocirurgia do Hospital Heliópolis, Hosphel, SP, baseado na história clínica, nos achados dos exames físico- neurológicos, estudo eletroneuromiográfico e teste de anticolinesterase com cloreto de edrofônio (Tensilon (B). A gravidade do quadro clínico e os sintomas destes pacientes foram avaliados e classificados, segundo critérios da Fundação de Miastenia Grave da América (MGFA) ${ }^{15}$ (Quadro 1). A distribuição é apresentada, conforme a Tabela1.

Os diagnósticos histológicos foram: timo normal $(22,8 \%)$, hiperplasia verdadeira $(13,6 \%)$, hiperplasia linfóide (50\%), e timoma maligno $(13,6 \%)$. Os timomas foram classificados de acordo com a proposição de Masaoka e Monden ${ }^{16}$ : dois encontravam-se em estádio II e um paciente em estádio I.
Tabela 1 - Pacientes, segundo a classificação clínica da Fundação de Miastenia Grave da América (MGFA) ${ }^{15}$

\begin{tabular}{lcc}
\hline MGFA & Número de pacientes & $\mathbf{( \% )}$ \\
\hline I & 0 & 0,0 \\
II a & 1 & 4,5 \\
II b & 2 & 9,1 \\
III a & 7 & 31,9 \\
III b & 7 & 31,9 \\
IV a & 4 & 18,1 \\
IV b & 1 & 4,5 \\
V & 0 & 0,0 \\
\hline Total & $\mathbf{2 2}$ & $\mathbf{1 0 0 , 0}$ \\
\hline
\end{tabular}

Cortes histológicos de tecido tímico fixados em formol a $10 \%$ e emblocados em parafina foram montados em lâminas previamente silanizadas (3-aminopropiltrietoxisilano, marca Sigma). Após a deparafinização e reidratação, foram

Quadro 1 - Classificação Clínica da Fundação de Miastenia Grave da América $(M G F A)^{15}$.

\begin{tabular}{|c|c|}
\hline CLASSE I & $\begin{array}{l}\text { Qualquer fraqueza do músculo ocular. } \\
\text { Fraqueza ao fechamento ocular. } \\
\text { Força normal em outros músculos. }\end{array}$ \\
\hline CLASSE II & $\begin{array}{l}\text { Fraqueza menor em outros músculos, além do músculo ocular. } \\
\text { Fraqueza do músculo ocular de qualquer gravidade. }\end{array}$ \\
\hline II a & $\begin{array}{l}\text { Predominantemente, acometendo músculos dos membros, tronco ou ambos. } \\
\text { Menor envolvimento dos músculos da orofaringe. }\end{array}$ \\
\hline II b & $\begin{array}{l}\text { Predominantemente, acometendo músculos da orofaringe, respiratórios ou ambos. } \\
\text { Menor envolvimento dos músculos dos membros, tronco ou ambos. }\end{array}$ \\
\hline CLASSE III & $\begin{array}{l}\text { Fraqueza moderada em outros músculos, além do músculo ocular. } \\
\text { Fraqueza do músculo ocular de qualquer gravidade. }\end{array}$ \\
\hline III a & $\begin{array}{l}\text { Predominantemente, acometendo músculos dos membros, tronco ou ambos. } \\
\text { Menor envolvimento dos músculos da orofaringe. }\end{array}$ \\
\hline III b & $\begin{array}{l}\text { Predominantemente, acometendo músculos da orofaringe, respiratórios ou ambos. } \\
\text { Menor envolvimento dos músculos dos membros, tronco ou ambos. }\end{array}$ \\
\hline CLASSEIV & $\begin{array}{l}\text { Fraqueza acentuada, acometendo outros músculos além do músculo ocular. } \\
\text { Fraqueza do músculo ocular de qualquer gravidade. }\end{array}$ \\
\hline IV a & $\begin{array}{l}\text { Predominantemente, acometendo músculos dos membros, tronco ou ambos. } \\
\text { Menor envolvimento dos músculos da orofaringe. }\end{array}$ \\
\hline $\mathrm{IV} \mathrm{b}$ & $\begin{array}{l}\text { Predominantemente, acometendo músculos da orofaringe, respiratórios ou ambos. } \\
\text { Menor envolvimento de músculos dos membros, tronco ou ambos. }\end{array}$ \\
\hline CLASSE V & $\begin{array}{l}\text { Intubação com ou sem ventilação mecânica, exceto quando usado no manejo rotineiro de pós-operatório. } \\
\text { O uso de sonda nasogástrica sem intubação coloca o paciente em CLASSE IV b. }\end{array}$ \\
\hline
\end{tabular}


imunocorados utilizando-se o método do complexo streptavidina-biotina-peroxidase (kit LSAB+, Dako). O bloqueio da peroxidase endógena foi alcançado, lavando-se as lâminas com água oxigenada a 3\% e a recuperação antigênica por calor úmido em panela de pressão, incubando-se por seis minutos em tampão citrato $10 \mathrm{mM}, \mathrm{pH} 6,0$. O anticorpo primário usado foi o antidesmina (clone D33; marca Dako, diluído a 1/200), incubado por 12 horas a uma temperatura de $8^{\circ} \mathrm{C}$. A reação foi revelada, utilizando-se diaminobenzidina (marca Sigma) como substância cromógena. As lâminas foram contra-coradas com hematoxilina de Carazzi, desidratadas e montadas. A avaliação dos resultados foi feita, contando-se o número de células coradas positivamente pela reação imuno-histoquímica em microscópio óptico convencional. As células mióides foram definidas como estruturas celulares alongadas, isoladas ou em pequenos agrupamentos, coradas em castanho. Foi tomado cuidado para não se confundir com pequenos vasos, cujas paredes, eventualmente, poderiam estar coradas pela reação imunohistoquímica. As lâminas foram examinadas aleatoriamente em campo de pequeno aumento para definir-se a área de maior concentração das células mióides ("hot spots"). A seguir, passou-se à contagem propriamente dita em campo de 200x. Os resultados foram expressos como o número de células mióides por área de maior concentração "hot spot" em campo de 200x.

Teste de Mann - Whitney foi empregado para comparar o número de células mióides em relação à raça e sexo e a análise de variância por postos de Kruskal - Wallis para comparar o número de células mióides no timo em cada tipo histológico. Fixou-se em 0,05 ou $5 \%(\alpha \leq 0,05)$ o nível de rejeição da hipótese de nulidade, assinalando-se com um asterisco o valor significante.

\section{RESULTADOS}

Foi feita a análise da contagem das células mióides nos timos com o diagnóstico anátomo-patológico de normal, hiperplasia verdadeira, hiperplasia linfóide e timoma maligno. A correlação com as diferentes variáveis é descrita a seguir.

As células mióides foram mais freqüentes na raça negra (média de 29,4) que na raça branca (média de 17,8), mas este resultado não foi significante $(\mathrm{p}=0,78)$.

O número de células mióides não variou significantemente segundo o sexo $(\mathrm{p}=0,24)$ mas o grupo feminino apresentou mais células mióides, em média de 23,2 contra 13 encontradas no grupo masculino (Tabela 2).

Tabela 2 - Número médio de células mióides em timos de pacientes miastênicos, segundo a faixa etária.

\begin{tabular}{ccc}
\hline Idade em anos & Número de pacientes & Média de células \\
\hline $0-20$ & 5 & 22,4 \\
$20-40$ & 14 & 21,7 \\
$40-60$ & 2 & 0,0 \\
$60-80$ & 1 & 33,0 \\
\hline
\end{tabular}

Tabela 3 - Correlação entre o número médio de células mióides em timos de pacientes e a classificação clínica da Fundação de Miastenia Grave da América $(M G F A)^{15}$.

\begin{tabular}{lcc}
\hline MGFA & Número de pacientes & Média de células mióides \\
\hline I & 0 & 0,0 \\
II a & 1 & 0,0 \\
II b & 2 & 8,5 \\
III a & 7 & 26,7 \\
III b & 7 & 21,0 \\
IV a & 4 & 19,5 \\
IV b & 1 & 20,0 \\
V & 0 & 0,0 \\
\hline
\end{tabular}

Os valores médios das células mióides (Tabela 3) mostram uma predominância no grupo de pacientes da classe clínica III a e apresentam um valor médio das células mióides de 26,7 .

A coloração pelo método imuno-histoquímico com anticorpo anti desmina, evidenciou as células mióides nos cortes histológicos de timo normal, hiperplasia verdadeira e hiperplasia linfóide. Estavam distribuídas na região medular, às vezes, na transição corticomedular predominamente em torno dos corpúsculos de Hassall, embora pudessem ser encontradas isoladas e de modo irregular pelos tecidos. As áreas com maior densidade podiam ser verificadas em qualquer campo dentro dos limites dos cortes histológicos (Figura 1).

Não foram encontradas células mióides nos cortes histológicos de timomas malignos e em um paciente com timo normal (Tabela 4).

\section{DISCUSSÃO}

Nesta casuística, a análise histológica coincide com a literatura ${ }^{17,18}$. O timo era normal em $22,8 \%$ dos casos e em

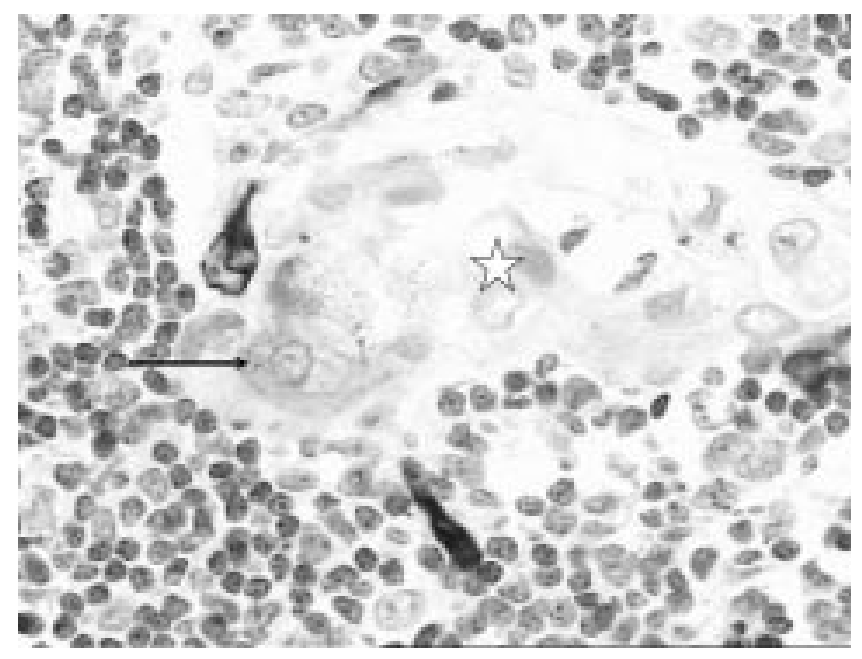

Figura 1 - Microfotografia de reação Imuno-histoquímica com anticorpo antidesmina para demonstrar aspecto citológico das células mióides em hiperplasia linfóide. Verifica-se a conformação fusocelular (seta fina), com núcleo excêntrico (seta grossa) e distribuição em torno do corpúsculo de Hassall (estrela) (Hematoxilina-Eosina, aumento de $400 \mathrm{X}$ ) 
Tabela 4 - Número de células mióides segundo o tipo histológico do timo.

\begin{tabular}{lcccc}
\hline Tipo Histológico & Número de Células & Média & Desvio Padrão & Mediana \\
\hline Timo normal & $0,21,33,35,37$ & 25,2 & 13,8 & 33 \\
Hiperplasia verdadeira & $17,24,85$ & 42 & 30,5 & 24 \\
Hiperplasia linfóide & $6,6,10,13,15,17,19,20,22,33,36$ & 17,9 & 9,3 & 17 \\
Timoma Maligno & $0,0,0$ & 0 & 0 & 0 \\
\hline
\end{tabular}

$77,2 \%$ havia alteração tímica: 13,6\% eram timomas e 63,6\% eram hiperplasias.

A severidade clínica da miastenia grave é, geralmente, medida pelo grau de acometimento funcional e pelos locais afetados. A classificação utilizada com mais freqüência na literatura é baseada no trabalho de Osserman ou de sua modificação ${ }^{19}$. Esta classificação tem sido criticada por ser subjetiva e sub quantificar os sinais e sintomas por inclusão na evolução clínica, categoria de atrofia muscular e forma neonatal de miastenia ${ }^{20}$. Para melhor avaliar e quantificar a intensidade clínica para a análise comparativa, que seria útil para várias intervenções terapêuticas utilizadas em estudos de miastenia grave, a Fundação de Miastenia Grave da América- MGFA ${ }^{15}$ elaborou uma nova proposta de classificação (Quadro 1) que foi usada neste estudo. Seguindo a classificação, a maioria dos pacientes do presente estudo situou-se na classe III (63,8\%). Tivemos dúvidas se a quantidade de células mióides influencia o estadiamento clínico da miastenia grave. Achamos que há influência das células mióides na miastenia grave, mas pela observação de número médio maior na classe III estatisticamente não significante consideramo-nos impossibilitados de fazer tal correlação. Será que tivemos maior número de células porque a maioria dos pacientes encontrava-se no estádio III ou foi esta quantidade maior que definiu a classificação clínica? Esta talvez seja uma linha de investigação futura correlacionando o número médio de células mióides com a classificação clínica e prognóstico.

A classificação histológica do timo adotada no estudo facilitou a melhor análise pela diferenciação das hiperplasias ${ }^{21}$. Nestas, o maior número médio de células mióides foi encontrado no tipo verdadeiro, embora a maioria dos timos seja do tipo linfóide, fortalecendo a idéia de separar os grupos, ao invés de agrupá-los somente como hiperplasias, distinção histológica também observada em outros trabalhos ${ }^{13,22}$.

Na literatura, vários métodos são referidos para evidenciar as células mióides em timos humanos e de outras espécies: hematoxilina, hematoxilina e eosina, ácido periódico de Schiff (PAS), hematoxilina de ácido fosfotúngstico (PTAH), anticorpo antimioglobina e anticorpo antidesmina ${ }^{8,10,14,16,22-24}$. Preferimos utilizar marcador imuno-histoquímico antidesmina com base nos relatos da literatura que demonstraram melhor identificação das células mióides em razão da grande quantidade de desmina existente nelas ${ }^{11,13,14}$. As células mióides são desmina positivas e, raramente, positivas para mioglobina ${ }^{14}$. No presente estudo, as células mióides foram identificadas e quantificadas em 18 pacientes $(81,8 \%)$, sendo ausentes em três pacientes com timoma maligno e um paciente com timo normal. Nosso resultado confirma que o anticorpo antidesmina é melhor como método de identificação das células mióides, pois conseguimos resultados similares aos da literatura ${ }^{11,14}$.

Nosso estudo apresentou três pacientes com diagnóstico de timoma maligno onde não foram observadas células mióides. Os trabalhos que apresentaram células mióides em timomas, eram de tipo histológico epitelial, mas em nosso estudo eram do tipo fusocelular ${ }^{8,24}$. O tipo histológico fusocelular é o menos freqüente do padrão celular encontrado nos timomas. Pela análise de nossos resultados, não foi possível chegar a uma conclusão sobre a influência de timomas ou seus tipos histológicos nas células mióides e miastenia grave, mas também não podemos negar a existência de células mióides em timomas baseados em relatos da literatura.

Em um timo normal do presente estudo, não foram identificadas células mióides. Isto pode ser interpretado como sendo um dos 10 a $20 \%$ dos pacientes miastênicos que não apresentaram anticorpos anti-receptores de acetilcolina ao exame de radioimunoensaio ${ }^{25,26}$. Apesar da não detecção desses anticorpos, sua presença já foi comprovada pela reprodução de miastenia grave, pela transferência passiva com o uso de imunoglobulina do soro desses pacientes em $\operatorname{ratos}^{27,28}$. Assim, podemos concluir que estes pacientes apresentam menor quantidade de células mióides, gerando menor quantidade de anticorpo anti-receptor de acetilcolina não detectável ao exame ou apresentam receptor de acetilcolina tipo fetal que é detectável em até $7 \%$ dos pacientes ${ }^{29}$. Em nossa opinião, as células mióides são desencadeantes do processo auto-imune culminando na miastenia grave, fato este já descrito. As células mióides apresentam dois tipos de receptores de aceticolina (AChR), o fetal e maduro ou de adulto, dependendo do tipo e alteração de algum fator influenciando direitamente as células mióides (por exemplo, apoptose) ou os próprios AChR que em certa quantidade podem gerar este processo. Demonstrou-se que os pacientes miastênicos e não miastênicos apresentavam quantidades iguais de células, mas os miastênicos demonstraram sempre maior quantidade de anticorpo anti $\mathrm{AChR}$, confirmando os aspectos auto imunes de miastenia grave e, em nossa análise, as fontes desses anticorpos são as células mióides ${ }^{16}$.

Os resultados observados permitem-nos concluir que as células mióides podem ser identificadas e quantificadas pelo método imuno-histoquímico com anticorpo antidesmina, não havendo correlação entre a quantidade de células mióides 
por unidade de área em cortes histológicos de timo e variáveis demográficas, clínicas e patológica. No timoma do tipo histológico fusocelular em pacientes com miastenia grave não encontramos células mióides identificáveis com anticorpo antidesmina.

Apesar da pequena casuística, nossos resultados estão em concordância com a maioria dos estudos da literatu- ra relatados anteriormente, mas um trabalho envolvendo uma casuística maior e um método mais sensível para identificar estas células nos timomas, constitui-se em uma linha de pesquisa muito promissora. Assim, será possível esclarecer as dúvidas ainda persistentes como a influência e significância de células mióides em pacientes não miastênicos e o porque de sua ativação em miastenia grave.

\begin{abstract}
Background: To detect and quantify myoid cells in thymus of patients with myasthenia gravis, establishing possible correlation between the amount of myoid cells and demographics, clinics, and pathological variables. Methods: thymic specimens of 22 patients (16 women and six men, age ranging from 12 to 61 years, were analyzed through immunohistochemistry with monoclonal antibody anti-desmin (Dako - D33). They were submitted to tymectomy, between 1981 and 1995, in the Thoracic Surgery Department of Hospital Heliópolis, São Paulo, Brazil, as part of the treatment for myasthenia gravis. Results: The largest mean valves of myoid cells were found in the thymus of patients from the black race $(29.4: 17.8)$, female $(23,2: 13,0)$ and with ages between 60 and 80 years old (average of 33.0) years old according to the the clinical classification of the Myasthenia Gravis Foundation of America (MGFA), the largest average of myoid cells (26.7) was found in class III and being the histological type of True Hyperplasia (average 42.0). The myoid cells were identified in 11 thymus with Lymphoid Hyperplasia, in three with True Hyperplasias and in four with Normal thymus. The malignant thymoma (three) and a normal thymus did not present myoid cells. Conclusion: The myoid cells can be identified and quantified by the immunohistochemistry method with monoclonal antibody anti-desmin, however there is no correlation between the amount of myoid cells and demographic, clinics, pathological variables. They were not identified in spindle cells tymoma.
\end{abstract}

Key Words: Myoid cells; Thymus; Immunohistochemical.

\section{REFERÊNCIAS}

1. Adams RD,Vitor M. Principles of neurology. 4th ed. New York :McGraw-Hill, 1989; 1150-167.

2. Pascuzzi RM. The History of myasthenia gravis. Neurol Clin, $1994 ; 12: 231-42$.

3. Cunha FMB, Scola RH, Werneck LC. Miastenia grave, Aspectos Históricos. Arq Neuropsiquiatr, 1999; 57: 531-6.

4. Castleman B, Norris EH. The pathology of thymus in myasthenia gravis: A study of 35 cases.Medicine (Baltimore), 1948; 38:27-58.

5. Van Der Geld HWR, Oosterhuis HJGH.- Muscle and thymus antibodies in myasthenia gravis. Vox Sang, 1963; 8:196-204.

6. Chang CE, Lee CY. Isolation of neurotoxins from the venom of bungarus multicinctus and their modes of neuromuscular blocking action. Arch Pharmacodyn Ther, 1962; 144:241-57.

7. Van De Velde RKL, Friedman NB.- The thymic "Myoidzellen" and myasthenia gravis. JAMA, 1966; 198:287- 8.

8. Van De Velde RKL, Friedman NB. Thymic myoid cells and myasthenia gravis. Am J Pathol, 1970; 59:347-67.

9. Van De Velde RKL, Friedman N B. Muscular elements in the thymus. Anat Rec, 1967; 157: 392-3.

10. Raviola E, Raviola G. Striated muscle cells in the thymus of reptiles and birds: An electron microscopic study. Amer J Anat, 1967; 121:623-46.

11. Kirchner T, Hoppe F, Schaike B, Muller-Hennelink HK. Microenvironment of thymic myoid cells in myasthenia gravis. Virchows Arch Cell Pathol, 1988; 54:295-302.

12. Schluep M, Willcox N, Vincent A, Dhoot GK, Newsom-Davis $\mathrm{J}$. Acetylcholine receptors in human thymic myoid cells in situ: An immunohistological study. Ann Neurol, 1987;22: 212-22.

13. Judd RL, Welch SL. Myoid cell differentiation in true thymic hyperplasia and lymphoid hyperplasia. Arch Pathol Lab Med, 1988; 112:1140-44.
14. Zoltowska A. Myoid and epithelial cell differentiation in myasthenic thymus. Thymus, 1991; 17:237-48.

15. Jaretzki A, Barohn RJ, Ernstoff RM, Kaminski HJ, Keesey JC, Penn AS, Sanders DB. Myasthenia gravis: recommendations for clinical research standards. Ann Thorac Surg, 2000; 70:32734.

16. Masaoka A, Monden Y. Comparison of the results of transesternal simple, transcervical simple and extended thymectomy. Ann NY Acad Sci, 1981; 377:755-65.

17. Malhotra V, Tatke M, Khanna SK, Gondal R. Thymic histology in myasthenia gravis.Indian J Chest Dis Allied Sci, 1992; 34:11721.

18. Lloréns Figueroa, JA. Miastenia gravis. Una enfermedad poco conocida. Avances Medicos de Cuba, 2001; 8: 42-6.

19. Osserman KE. Clinical aspects. In : Osserman KE. Myasthenia gravis. New York: Grune \& Stratton, Inc, 1958; 79-80.

20. Drachman DB. Myasthenia gravis : Review Article. N Engl J Med, 1994; 330:1797-1810.

21. Levine GD, Rosai J. Thymic hyperplasia and neoplasia: A review of current concepts.Hum Pathol, 1978; 9:495-515.

22. Hayward ,AR. Myoid cells in the human foetal thymus. J Pathol, 1972; 106: 45-8.

23. Bornemann A, Kirchner T. Thymic myoid cell turnover in myasthenia gravis patientes and in normal controls. Virchows Arch, 1998; 432:357-61.

24. Furuya A, Kobayashi T, Kameda N, Tsukagoshi H: Human myasthenia gravis thymic myoid cells: de novo immunohistochemical and intracellular electrophysiological studies.J Neurol Sci, 1991; 101:208-20.

25. Lindstrom JM, Seybold ME, Lennon VA, Whittingham S, Duane DD. Antibody to acetylcholine receptor in myastbenia gravis. Prevalence, clinical correlates, and diagnostic value. Neurology, 1976; 26:1054-9. 
26. Howard FM Jr, Lennon VA, Finley J, Matsumoto J, Elveback LR. Clinical correlations of antibodies that bind, block, or modulate human acetylcholine receptors in myasthenia gravis. Ann N Y Acad Sci , 1987;505:526-7.

27. Drachman DB, Silva S, Ramsay D, Pestronk A. Humoral pathogenesis of myasthenia gravis. Ann N Y Acad Sci, 1987; 505:90-105.

28. Drachman DB, Silva S, Ramsay D, Pestronk A. "Sero negative" myasthenia gravis: a humorally mediated variant of myasthenia. Neurology, 1987; 37:1:214. .
29. Wakkach A, Poea S, Chastre E, Gespach C, Lecerf F, De La Porte S, Tzartos S, Coulombe A, Berrih-Aknin S. Establishment of a human thymic myoid cell line. Phenotypic and functional characteristics. Am J Pathol, 1999; 155:1229-40.

Endereço para correspondência:

Prof. Dr. Abrão Rapoport

Rua Iramaia, 136 - Jd. Europa

CEP: 01450-020 - São Paulo - SP 